\title{
Optical standards
}

This content has been downloaded from IOPscience. Please scroll down to see the full text. 1899 Trans. Opt. Soc. 14

(http://iopscience.iop.org/1475-4878/1/1/302)

View the table of contents for this issue, or go to the journal homepage for more

Download details:

IP Address: 147.8.31.43

This content was downloaded on 01/10/2015 at 12:20

Please note that terms and conditions apply. 
OPTICAL STANDARDS.

Paper by Mr. Lionel Luaurance, Member.

Read before the Optical Societ!l on Necember 21st, 1899.

M R. PRESIDENT and gentlemen: I feel that your committee has the author of the first paper read before you. The selection of a suitable subject caused me considerable anxiety, but since I can hardly hope that this paper will be altogether worthy of the occasion, I ask for, and trust that you will extend to me your indulgence for any shortcomings in style and matter.

The subject selected is Optical Standards, and it therefore offers no pretence to being immediately instructive. It is intended rather for the purpose of promoting discussion-let us hope, not a heated discussion-which may ultimately prove of benefit to the optical industry.

The utility of standards in all industries has long been recognised and they are no less necessary in the optical than in any other trade, whether they be standards of measurement, of size, of quality or of design.

There is a real necessity for standardising many of the data connected with the every day requisites of the up-to-date retail Optician, so that, without burdening orders with too many details, his exact wants may be supplied without undue chance of error. Four subjects . are touched upon in this paper. They are: The calibration of lenses and frames, angle notation, colour standards, and spreads of bridges.

The advanced system of optical trading, as regards spectacles and eyeglasses, consists principally in fitting to each customer a particular frame with particular lenses, exactly suited to his requirements, the ordering of which involves a mass of minute details; and a system of standards must reduce the time and labour that have to be expended on each transaction. But independent and individual standards are next to useless; to attain the full measure of utility, such must 
be universally adopted by all manufacturers and by all their customers.

For example, if an Optician knows that eyes of certain calibre will serve the purpose for which the spectacle is required, he need neither take nor give the exact details of length and depth, nor need a work man spend unnecessary time in construction to dimensions given; eyes of such calibre can be kept in stock by the wholesaler and supplied at once as required.

At present the calibration of the eyes of spectacles, the angle notation of cylindrical axes, the numeration of colours and the nomenclature of bridges, as employed by each wholesale house, are without regard to any general system; so much is this the case that, if a retail Optician does not wish to incur chances of delay and loss, he must be provided with the special prescription form, the catalogue, the sample set of coloured glasses and the spread rule made by a particular honse, before he dare order from it a pair of tinted spherocylindrical lenses in a certain sized frame.

Of course there is a point in every line of manufacture where a standard size or design does not adequately satisfy requirements, and a special pattern is wanted; but in the vast majority of cases the "standard" serves, and the "special" is needed only occasionally.

If standards are appropriate and correct, very frequently indeed the articles made to them are not only chenper, but more efficient and more attractive than specially designed ones. It is not necessary in this paper to dilate upon the close connection that exists betweer standardisation and the employment of machinery in manufacture, the latter tending so greatly to the development of the trade by the pro duction of efficient goods at reasonable prices.

\section{Angle Notation.}

The subject of standardising angle notation, as regards the setting of the axes of cylindrical lenses, is one that may be considered first. It is needless to attempt to show how many ways there are of indicating the position of a cylindrical axis; usually that employed by an Optician follows the notation of his own trial frame or that of the prescription form that a particular Oculist happens to use.

Nor do the notations of the trial frame and the prescription form always correspond ; consequently, he may have to make a calculation when transferring results obtained from the one to the other. The 
calculation may indeed be quite easy, but the act remains that unnecessary work has to be done.

So great is the uncertainty of numeration alone, as numeration now obtains, that Oculists generally mark on their prescriptions the cylindrical axis as being so many degrees up or down and out or in, nasal or temporal, which indication of the position of the axis is so very definite that it cannot be interpreted in any but, say, four different ways. The chances of error are, it is true, minimised if an oblique stroke accompanies the indicating number, but even then, say, $40^{\circ}$ down and out indicates a direction so nearly midway between the horizontal and the vertical that there may still be doubt whether the $40^{\circ}$ out is to be measured from the former or from the latter, and strokes to indicate the position of the axes cannot well accompany speech, nor be transmitted by telephone or telegraph.

The suggested system of standard angle notation is that of numbering from zero on the right hand side of the eye, as it faces the Optician and proceeding upwards, the eye being that of a human being, of a trial frame or of a spectacle. There are two reasons why this notation is superior to any other.

First, it is the ordinary trigonometrical notation of angles, and second, it is already the standard in Canada and in the United States, no other being there used. Also to a certain extent, it is the standard in India, Mexico, Central and South America, the West Indies and Australia. Optical prescriptions ought to be capable of correct interpretation in any country, no matter where written.

It is so far the only method that is recognised even in England as being, to some extent, the standard, inasmuch as it does not need to be accompanied by explanatory words or lines. And thanks to its having been adopted by our trade organ, The Optician, many Opticians know at once what is meant by, say, $30^{\circ}$, without reference to any particular trial frame or special prescription form.

It is necessary to be quite clear as to what is meant by right and left in optics. By the right or the left eye of a frame, we mean that which is intended for the corresponding eye of the customer, and here no exror can arise. But when we refer to the right side of an eye, we indicate that which is opposite to the Optician's right hand, and therefore here the expressions right and left differ from the medical and optical points of view.

In medical phraseology, "right" and "left" refer to the right and left of the patient, while in optics, these terms are used rather in a mathe- 
matical sense, right and left being respectively to the manipulator's right and left hands.

If the numbered are is on the upper part of the trial frame or prescription form, the notation commences, as stated, with zero on the Optician's right of each eye, that is, on the nasal side of the right eye and on the temporal side of the left eye, and proceeds upwards towards the vertical, which is $90^{\circ}$, and then downwards to $180^{\circ}$. If the numbered are is below, the notation starts at zero to the left, that is on the temporal side of the right and on the nasal side of the left eye, and proceeds downwards over towards the right. The notation is the same for both eyes.

It is of great importance that a particular starting point for the notation should be fixed, but it is of even greater importance that the two eyes should be similarly numbered. Four reasons for this can be given :-

First. In conversation or writing, if a certain meridian, say $40^{\circ}$, is mentioned, it conveys to the mind of the hearer or reader a definite idea of the indicated position from an optical point of view.

Second. A certain lens, say, +2 sph. $\subsetneq+2$ cyl. ax. $40^{\circ}$, No. 4 calibre, can be ordered by card or telegram without the necessity of stating whether it is for the right or for the left eye. In telegraphing, this is a decided advantage.

Thivd. In retinoscopy, when a movement of the shadow along a certain oblique meridian is mentally interpreted, one has not to consider whether it is at $120^{\circ}$ or at $60^{\circ}$ according to whether it is in the right or the left eye.

Fouth. Astigmatic charts, inclinometers, ophthalmometers and other optical instruments need but a single notation when it is similar for both eyes; if different, the instrument must be doubly graduated, once for the right and once for the left, unless indeed a separate instrument is provided for each eye.

Take, for instance, the Maddox axis finder; when different notations are employed, the user has not only to consider whether he has located the meridian of greatest or that of least refraction, but also whether he has the numeration of a right or of a left eye to deal with.

Suppose an Optician wishes to mark down the exact axial meridian of a single lens, say, $+1 \mathrm{sph} .=+1 \mathrm{cyl}$. ax. $30^{\circ}$. If the so-called symmetrical notation is employed, he must write, that if the lens be for the right eye, and the cylindrical to the front, it is axis $30^{\circ}$; if the spherical is to the front, it is axis $150^{\circ}$. But if the lens be for the 
left eye, then it is axis $150^{\circ}$ if the cylindrical is to the front, and $30^{\circ}$. if the spherical is to the front. Let us try to do away with as much uncertainty and useless labour as possible. A standard notation similar for both eyes is a necessity among advanced and accurate Opticians.

The suggested notation for both eyes is here illustrated.

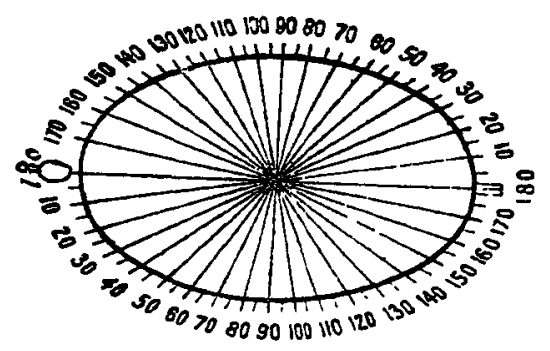

Another angle notation which is sure to be suggested is that which commences at zero for both eyes, either on the nasal or on the temporal sicle. The principal, in fact the only, argument in its favour is that its numeration is symmetrical in respect to the middle line of the face, in the same way as astigmatism; the meridians of greatest and of least refraction in both eyes being generally, when oblique, similarly inclined towards or away from the nose. But no real advantage accrues from the adoption of such a notation.

If the proposed standard be adopted every Optician will know that two such inclinations as, say $75^{\circ}$ in the one and $105^{\circ}$ in the other eye are symmetrical as regards the medial line.

If possible there should be in optics no departure from mathematical procedure; and this is maintained when the angle notation fur both eyes is similar to the ordinary notation of angles in trigonometry.

\section{Spread Rules.}

The diversity in spread rules, both as to the dimensions of the spreads and their numeration or lettering, illustrates how successfully we can import confusion into a very simple matter. Each spread rule is, as a rule, altogether useless except when ordering from the house by which it was supplied.

The height and set in or out, with the other needful dimensions, suffice in most cases when ordering a frame; but when the number of a 
spread is given, it should be capable of correct interpretation by any one in the optical trade, just as much as the height of the bridge or the interpupillary distance.

It seems as if there could be no very scientific basis for standards in spreads of bridges; it is merely a question of obtaining a sufficiently varied series suitable for the different shapes of noses the Optician meets with in his practice.

Let the spreads be indicated by numbers 1 to 9 , and let each spread be made $1 \mathrm{~cm}$. deep; standardisation consisting of a definite width being given to each spread at $2 \mathrm{~mm}$. and at $7 \mathrm{~mm}$. from the vertex of the arch. Measurement of the width of the bases themselves would be too indefinite for standards.

Starting with No. 1, which has a width of $5 \mathrm{~mm}$. at $2 \mathrm{~mm}$. from the vertex of the arch, and a width of $7 \mathrm{~mm}$. at a distance of $7 \mathrm{~mm}$. from the vertex of the arch, the spreads increase regularly by $1 \mathrm{~mm}$. at the higher and by $2 \mathrm{~mm}$. at the lower position, up to widths of 13 and $28 \mathrm{~mm}$. This seems to be simple enough at any rate.

\section{TABLE I.}

Following is the suggested list. Spreads $1 \mathrm{~cm}$. in depth.

\begin{tabular}{|c|c|c|c|c|c|}
\hline \multirow{10}{*}{$\begin{array}{c}\text { No. } \\
1 \\
2 \\
3 \\
4 \\
5 \\
6 \\
7 \\
\varepsilon \\
9\end{array}$} & \multicolumn{3}{|c|}{$\begin{array}{l}\text { WIDTH 2MM. FROM } \\
\text { THE V.ERTEX }\end{array}$} & \multicolumn{2}{|c|}{$\begin{array}{l}\text { WIDTE 7MM. FROM } \\
\text { THE VHRTEX. }\end{array}$} \\
\hline & & $5 \mathrm{~mm}$. & . & .. & $7 \mathrm{~mm}$ \\
\hline & . & $6 \mathrm{~mm}$. & & & $9 m u$. \\
\hline & & $7 \mathrm{~mm}$. & .. & $\cdots$ & $11 \mathrm{~mm}$. \\
\hline & & $8 \mathrm{~mm}$. & $\ldots$ & $\ldots$ & $13 m m$. \\
\hline & & $9 \mathrm{~mm}$. & .. & . & $15 \mathrm{~mm}$. \\
\hline & . & $10 \mathrm{~mm}$. & . & ... & $17 \mathrm{~mm}$. \\
\hline & . & $11 \mathrm{~mm}$. & $\ldots$ & . & $14 \mathrm{~mm}$. \\
\hline & & $12 \mathrm{~mm}$. & .. & . & $21 щ m$. \\
\hline & .. & $13 \mathrm{~mm}$. & ... & & $23 \mathrm{~mm}$ \\
\hline
\end{tabular}

Some rough cuts showing the actual dimensions, are here shown.

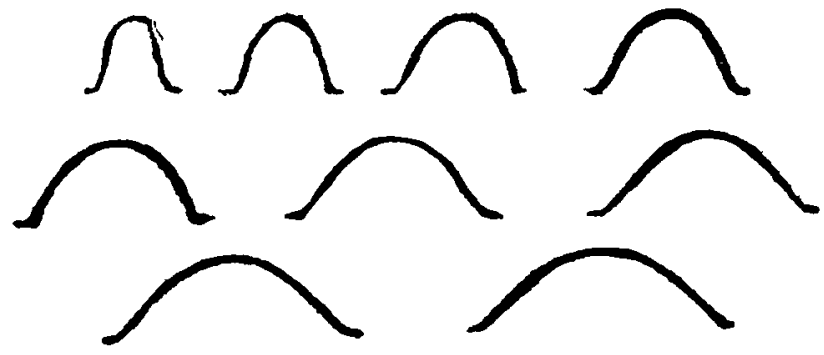




\section{Calibration of Lenses and Frames.}

For the standardisation of the calibration of lenses and the eyes of spectacles, any truly scientific basis also does not seem to be possible. Here arise questions of appearance, of custom and of commercial expediency.

Most of the leading wholesale houses in the trade were-for the purposes of this paper-asked for the loan of a set of calibred lenses such as they ordinarily manufacture or sell ; many of them courteously responded. It was found-notwithstanding that the indicating letters or numbers often varied-there were many of the most useful sizes common to almost every house. Thus, for instance, the No. 7 of Messrs. A, the No. 2 of Messrs. B, the No. F of Messrs. C, and the No. 14 of Messrs. D, were exactly alike in their dimensions.

It is almost unnecessary to point out that the standardisation of certain sizes in frames and lenses does not in any way affect the manufacture or sale of special lines by any individual house. Each manufacturer could still make, if he found it convenient or advisable, particular styles of spectacles and pinces-nez whose calibration varied from the standards adopted, and in addition might keep and supply such lenses and frames, interchangeable with those sold by other dealers.

Since the wire of the eye of a spectacle "gires" to a certain extent, a certain sized spectacle eye can be fitted with several lenses whose two diameters differ from one another; only in all cases, the perimeter of the lenses must be equal to the measurement of the inside of the eye wure.

Therefore, in order to standardise lenses and eye pieces of frames, we must take the circumferential measurement and not the two diameters of an oval; thus allowing various forms of lenses to be equally standard on the basis of a given circumference of a circle.

There being certain sizes in lenses and eye pieces common to most of the leading wholesale optical trade, it was not difficult to decide on the standards to be suggested.

These universal sizes to which uniform numbers are given form the basis of the proposed standards.

Taking eertain calibred oval lenses in common use by the trade, the two diameters were measured. From the formula

$$
\pi \quad \sqrt{\frac{a^{2}+b^{2}}{2}}
$$

where $a$ and $b$ respectively are the long and the short diameters of the ellipses which are the usual ovals of spectacle lenses, we obtain the 
perimeters of these. And giving numbers 1 to 9 to them, they are suggested as the standards which should be adopted. No. 6 was the largest size measured, but the scale is made for the three larger sizes in order to complete the series.

\section{TABLE 2.}

The following table gives approximately the circumferences and diameters of the lenses and eye wires most commonly used in the trade.

No.

$\mathbf{1}$
$\mathbf{2}$
$\mathbf{3}$
4
$\mathbf{5}$
6
7
8
9
Circumference IN MIM.

... 92

$\cdots$

$$
\cdots
$$

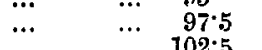$$
\cdots \quad \ldots \quad 102 \cdot 5
$$$$
\cdots \quad \cdots \quad 106
$$$$
\cdots \quad \cdots \quad 113
$$$$
\text { ... } 117
$$$$
\begin{array}{ll}
129 \cdot 5 \\
\cdots \\
135
\end{array}
$$

Diameter of Cirche

\begin{tabular}{|c|c|c|}
\hline & & $\begin{array}{l}\text { IN MM. } \\
29 \cdot 25\end{array}$ \\
\hline & $\cdots$ & $\begin{array}{l}30 \cdot 25 \\
31\end{array}$ \\
\hline a. & 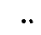 & $32 \cdot 5$ \\
\hline ".." & $\cdots$ & $\begin{array}{l}34 \\
36 \\
37 \cdot 25\end{array}$ \\
\hline & ... & $\begin{array}{l}41 \cdot 25 \\
43\end{array}$ \\
\hline
\end{tabular}

Now, having the above data to work upon, in order to produce, as standards, certain oval lenses which would be properly graduated, a convenient value was given to one of the two diameters required and the other was found by calculation.

$$
\text { Since } \pi \sqrt{\frac{a^{2}+\bar{b}}{2}}=\text { perimeter }
$$

it follows that

$$
\sqrt{2\left(\frac{\text { perimeter }}{\pi}\right)^{2}-\mathrm{a}^{2}}=\mathrm{b}
$$

Starting at $33 \mathrm{~mm}$. for the long diameter in the one scale and at 35 $\mathrm{mm}$. for the long diameter in the other, and increasing these lengths regularly, we obtain the following dimensions for a standard set of short oval and long oval lenses. And to make the table complete, there has also been obtained by direct measurements the sizes of a set of round oval and pantoscopic lenses, whose perimeter is, in each case, the same as that of the corresponding number of a circular and of an elliptical lens.

\section{TABLE 3.}

The proposed complete set of standard calibres for lenses and eye wires is as follows :-

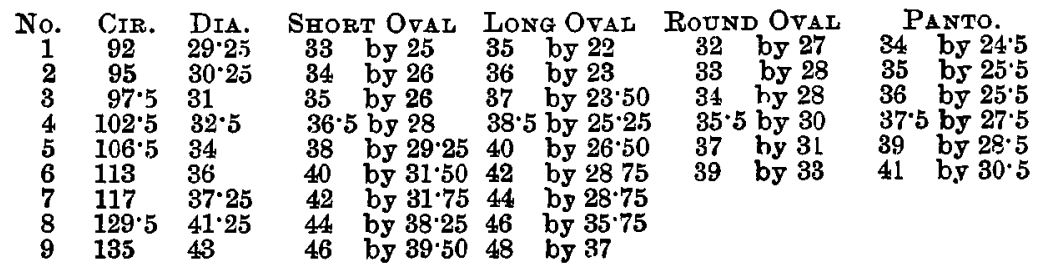


Thus a lens 35 by $26 \mathrm{~mm}$. or one that is 37 by $24 \mathrm{~mm}$. or one that is, say, 36 by $25 \mathrm{~mm}$. would equally be a standard number 3 oval, their perimeters being the same, namely $97.5 \mathrm{~mm}$.

The sizes Nos. 7, 8, and 9 oval are for globulars. Nos. 2, 4, and 6 round are respectively about equal in size to the $1 \frac{1}{4}$, the $1 \frac{3}{8}$ and the 1홀 inch round trial case lenses, the last being the size generally employed.

With a fair degree of approximation, No. 3 corresponds to the French 13 calibre, No. 4 to the $13 \frac{1}{2}$, and so on; but the French calibres seem rather uncertain. Grooved lenses would be of the same perimeter, measured in the groove, as ordinary lenses are, measured around the knife edge.

It must be observed that although the figures do not correspond cractly to those of the American standards, yet each proposed British standard lens has the same circumference as some one of the former, so that they are interchangeable. It is impossible to vouch for the precise accuracy of the figures given, careful verification is needed. The calculations, however, have been confirmed by direct measurements taken from a set of wires, carefully prepared for the purpose. of this paper by one of the wholesale firms.

\section{Coloured Glasses.}

The standardisation of colours is, it will be acknowledged, a subject beset with difficulties.

The standard that is suggested for smoked glasses is one which reduces, by one half, the intensity of transmitted light. Thus, if a candle is placed on one side of a grease spot photometer, and two similar candles at the same distance therefrom on the other side, the apparent intensity of the latter is reduced, by means of the standard smoked glass placed in front of them, so that it is equal to that of the single candle.

Or if a single candle is placed on one side of the photometer at a distance of 12 ins., and another covered by the standard smoked glass is placed on the other side at a distance of $8 \frac{1}{2}$ ins., the intensity of the second shall then be equal to that of the first. The squares of 12 and $8 \frac{1}{2}$ being respectively 144 and 72 .

The proposed standard smoked glass from rough experiments made, seem to correspond approximately to the usual trade No. 1 smoked; but the tints at present used by different firms often present somewhat cmbarrassing differences. The experiments, however, ought not to be 
made with the coloured light of candles, but with white solar light when determining the standard No. 1 smoked glass.

Standard No. 2 would be equal to two number ones placed together, No. 3 would be equal to three number ones placed together and so on up to some suitable dark shade, say No. 9. If lighter shades or intermediate shades were required, they would be numbered in half numbers, thus No. $\frac{1}{2}$ or $1 \frac{1}{2}$. These proposed standards, of course, refer to plane glasses, which obviously must be accepted as our basis of reference, since they only are used in trial cases.

Attempts to devise a standard for blue glass have been in vain; photometric calculations here seem to be valueless, because the nature of the light is altered by the coloured glass, but no doubt, there are, among the members of this Society, some whose scientific knowledge of these matters will enable them to suggest a basis of standardisation.

Dr. Lindsay Johnson, some time ago, read a paper before the Royal Photographic Society on a system of colour standards in connection with colour photography; but they being based on spectrum hues would be, it would seem, of little value in connection with coloured glass.

The ordinary cobalt glass is by no means a pure blue; it transmits a very fair proportion of red rays. Most of you know the spectrum blue glass invented by Dr. Lindsay Johnson, in conjunction with Mr. Pillischer, of Bond Street, and you, therefore, also know that it differs very considerably from the blue glass commonly employed in the optical industry. Whether indeed cobalt blue should be used at all for optical purposes is an open question, but it cannot be argued here.

In The Optician of September 5th, 1895, there is an article entitled "A scheme of colour standards" by J. H. Pillsbury. It treats of a method of systematising colour nomenclature and of forming a series of colour standards based on the hues of the solar spectrum and selected by a number of " colour experts."

These stundards were to be adopted as the foundation of all colour work; and although the difficulties of producing pigments which represent the colours of the solar spectrum were very great, still they seem to have been, to some extent, overcome, and six spectrum colours, namely, red, orange, yellow, green, blue, and violet, were defined as standards. These standard pigments, also, do not seem helpful in producing a standard blue in glass to be used for optical purposes.

Naturally, green is not of any very great importance, since it is lut 
little employed; but if we did find a scientific basis for a standard in blue, a similar method would, no doubt, also serve for the green. Failing some scientific basis, it might be suggested that an arbitrary blue should be selected of a tint that might be said to correspond in depth to that of the No. 1 smoked, and this taken as No. 1 standard; then No. 2 would be equal to two number ones placed together, No. 3 to three number ones, and so on; the same as with the smoked.

There are many other things connected with the optical trade which conld be standardised; doubtless, they will presently come to the front; for instance, no attempt has been made to deal with prism notation. This, as a subject of extreme complexity, may well be left for future consideration.

Instead of using the same numbers ranging from 1 to 9 or so for all optical standards, it would perhaps be as well to employ them only for the calibres of lenses and eye wires. For tints, the letters A to, say, $H$ or $J$ would serve, while for the spreads of bridges, we could have the numbers from 11 upwards or the letters from $\mathrm{J}$ onwards. Again, other series of numbers or figures could be adopted for standards in other matters. Or we could supply letters to qualify the numbers; thus $\mathrm{S} 1$ to $\mathrm{S} 9$ for smoked and B 1 to B 9 for blue glass, $\mathrm{C}$ 1 to $\mathrm{C} 9$ for calibres, $\mathrm{N} 1$ to $\mathrm{N} 9$ for bridges, and so on. But these are merely matters of detail.

We must expect to be told that there is no necessity for optical standards; that no wholesale or retail Optician experiences difficulty in interpreting and filling each and every order or prescription received from customers. Be this as it may, in respect to any particular house, in its dealing with its customers, the argument can apply only to that house and not to the trade as a body.

From the position of the Worshipful Company of Spectacle Makers in regard to the trade, their co-operation must be obtained in fixing those standards that the Optical Society may consider necessary and suitable. The charter of the Guild enables it, to a certain extent, to govern and regulate the tracle, and it is the prerogative and the duty of the Company to fix definitely all standards for the British Optical Industry. The Company has indeed made a start, since it has already fixed one standard, namely, that of knowledge of optics. As a matter of fact, there is no other body in this country, excepting the government that has sufficient influence or power to develop officially this imprrtant matter. The Guild is an independent authority and its decision would have the necessary weight with the trade. Already, as 
you are all aware, some four hundred of the most advanced Opticians in the country are freemen of the Company.

I am sure that you will join with me in thanking those wholesale houses who so readily placed at my disposal various articles which assisted materially in the preparation of this paper, and I trust that the discussion which will follow will be beneficial to the wholesale, and retail optical industries of the country by helping to clear up any difficulties which surround the arrival at, and the adoption of, a complete system of optical standards. 